\title{
Renoprotection and the Bardoxolone Methyl Story - Is This the Right Way Forward? A Novel View of Renoprotection in CKD Trials: A New Classification Scheme for Renoprotective Agents
}

\author{
Macaulay Onuigbo \\ College of Medicine, Mayo Clinic, Rochester, Minn., and Mayo Health System Practice-Based \\ Research Network, and Department of Nephrology, Mayo Clinic Health System, \\ Eau Claire, Wisc., USA
}

Key Words

Angiotensin receptor blockers - Angiotensin converting enzyme inhibitors - Renoprotection . Diabetes mellitus · Chronic kidney disease · Revisionist view · Novel classification scheme ·

Renoprotective agents

\section{Abstract}

In the June 2011 issue of the New England Journal of Medicine, the BEAM (Bardoxolone Methyl Treatment: Renal Function in CKD/Type 2 Diabetes) trial investigators rekindled new interest and also some controversy regarding the concept of renoprotection and the role of renoprotective agents, when they reported significant increases in the mean estimated glomerular filtration rate (eGFR) in diabetic chronic kidney disease (CKD) patients with an eGFR of 20-45 $\mathrm{ml} / \mathrm{min} / 1.73 \mathrm{~m}^{2}$ of body surface area at enrollment who received the trial drug bardoxolone methyl versus placebo. Unfortunately, subsequent phase IIIb trials failed to show that the drug is a safe alternative renoprotective agent. Current renoprotection paradigms depend wholly and entirely on angiotensin blockade; however, these agents [angiotensin converting enzyme (ACE) inhibitors and angiotensin receptor blockers (ARBs)] have proved to be imperfect renoprotective agents. In this review, we examine the mechanistic limitations of the various previous randomized controlled trials on CKD renoprotection, including the paucity of veritable, elaborate and systematic assessment methods for the documentation and reporting of individual patient-level, drug-related adverse events. We review the evidence base for the presence of putative, multiple independent and unrelated pathogenetic mechanisms that drive (diabetic and non-diabetic) CKD progression. Furthermore, we examine the validity, or lack thereof, of the hyped notion that the blockade of a single molecule (angiotensin II), which can 
only antagonize the angiotensin cascade, would veritably successfully, consistently and unfailingly deliver adequate and qualitative renoprotection results in (diabetic and non-diabetic) CKD patients. We clearly posit that there is this overarching impetus to arrive at the inference that multiple, disparately diverse and independent pathways, including any veritable combination of the mechanisms that we examine in this review, and many more others yet to be identified, do concurrently and asymmetrically contribute to CKD initiation and propagation to end-stage renal disease (ESRD) in our CKD patients. We conclude that current knowledge of CKD initiation and progression to ESRD, the natural history of CKD and the impacts of acute kidney injury on this continuum remain in their infancy and call for more research. Finally, we suggest a new classification scheme for renoprotective agents: (1) the single-pathway blockers that block a single putative pathogenetic pathway involved in CKD progression, as typified by ACE inhibitors and/or ARBs, and (2) the multiple-pathway blockers that are able to block or antagonize the effects of multiple pathogenetic pathways through their ability to simultaneously block, downstream, the effects of several pathways or mechanisms of CKD to ESRD progression and could therefore concurrently interfere with several unrelated upstream pathways or mechanisms. We surmise that maybe the ideal and truly renoprotective agent, clearly a multiple-pathway blocker, is on the horizon. This calls for more research efforts from all.

Copyright (C) 2013 S. Karger AG, Basel

\section{Introduction: The Ongoing Trial of Bardoxolone Methyl as a Renoprotective} Agent - Is This the Right Way Forward for Renoprotection?

In the June 2011 issue of the New England Journal of Medicine (NEJM), the BEAM (Bardoxolone Methyl Treatment: Renal Function in CKD/Type 2 Diabetes) trial investigators rekindled new interest and also some more controversy in the concept of renoprotection and the role of renoprotective agents, when they reported significant increases in the mean estimated glomerular filtration rate (eGFR) in diabetic chronic kidney disease (CKD) patients with an eGFR of $20-45 \mathrm{ml} / \mathrm{min} / 1.73 \mathrm{~m}^{2}$ of body surface area at enrollment who received the trial drug bardoxolone methyl versus placebo [1]. Patients receiving bardoxolone methyl had significant increases in the mean $( \pm$ SD) eGFR as compared with placebo at 24 weeks (with between-group differences of $8.2 \pm 1.5 \mathrm{ml} / \mathrm{min} / 1.73 \mathrm{~m}^{2}$ in the 25 -mg group, $11.4 \pm 1.5 \mathrm{ml}$ / $\mathrm{min} / 1.73 \mathrm{~m}^{2}$ in the $75-\mathrm{mg}$ group, and $10.4 \pm 1.5 \mathrm{ml} / \mathrm{min} / 1.73 \mathrm{~m}^{2}$ in the $150-\mathrm{mg}$ group; $\mathrm{p}<$ $0.001)$. The increases were maintained through week 52 , with significant differences of $5.8 \pm$ $1.8,10.5 \pm 1.8$, and $9.3 \pm 1.9 \mathrm{ml} / \mathrm{min} / 1.73 \mathrm{~m}^{2}$ in the different groups, respectively [1]. So we ask the question, as far as renoprotection is concerned, is bardoxolone methyl the right way forward? This question has been overtaken by recent events: in October 2012, the BEACON (Bardoxolone Methyl Evaluation in Patients with Chronic Kidney Disease and Type 2 Diabetes: The Occurrence of Renal Events) trial was terminated following observed safety concerns regarding bardoxolone methyl. This caveat applies to any further comments in this review pertaining to bardoxolone methyl.

As recognized by the BEAM investigators, current renoprotection paradigms depend generally on the use of angiotensin converting enzyme (ACE) inhibitors and/or angiotensin receptor blockers (ARBs), but in total, these agents have proved to be imperfect [1-4]. Despite the extensive, widespread and continued use of ACE inhibitors and ARBs both in the USA and worldwide over the last two decades, most estimates suggest that the progression of CKD to end-stage renal disease (ESRD) has continued, almost unabated, in CKD patients around the world [5-7]. The claims by the BEAM investigators in their June 2011 NEJM report of blood pressure-independent renoprotective effects of bardoxolone methyl are remarkable [1]. 
Nonetheless, such claims of blood pressure-independent renoprotection must be taken with a significant degree of circumspection, wariness and caution [2-4]. Besides, as is the case with ACE inhibitors and ARBs, more data is needed to fully and incontrovertibly substantiate such claims of blood pressure-independent renoprotection with any agent [2-4, 8]. It is worth mentioning that similar earlier claims of blood pressure-independent renoprotection by angiotensin blockade have been seriously challenged when Svensson et al. [8] of the HOPE investigators demonstrated post hoc that the patients in the ramipril (ACE inhibitor) arm of the HOPE trial had much lower blood pressure levels as measured by 24-hour ambulatory blood pressure monitoring than was previously reported.

To their credit, the BEAM investigators included CKD patients with mean baseline serum creatinine of $2.0 \mathrm{mg} / \mathrm{dl}$ at enrollment in the phase II trial of bardoxolone methyl [1]. This represents one of the highest mean baseline serum creatinine values at enrollment of any CKD randomized controlled trial (RCT) [9-16]. This would hopefully allow for a more justifiable extrapolation of the use of this agent to patients with similar (or higher) CKD stages if the drug is subsequently approved for use. Since previous CKD trials on ACE inhibitors and ARBs often recruited patients with more preserved kidney function, there has remained this unresolved debate and controversy regarding the efficacy, utility and safety of ACE inhibitors and ARBs in patients with more advanced CKD, as such patients have been frequently excluded from participation in previous CKD trials [2-4, 9-16]. Equally, the mean age of 67 years of the BEAM phase II trial cohort ranks again in the highest quartile of participants' age among modern CKD RCTs [9-16]. This would arguably again allow for a more justifiable extrapolation of study outcomes on bardoxolone methyl to older patients ( $>65$ years of age) [2-4, 9-16]. Furthermore, the even spread of the varying degrees of albuminuria among the BEAM phase II CKD trial participants is commendable and is more representative of the usual pattern of CKD patients seen in general nephrology practice [1-4]. Also, the relatively long duration (52 weeks) of the published phase II trial is noted, and it is hoped that the ongoing global phase III bardoxolone methyl trial, the BEACON trial, would be extended to at least 2 years at the minimum for every recruited study participant in order to allow for a fuller and more complete evaluation of the efficacy and safety of the bardoxolone methyl agent in diabetic stage IV CKD patients [1-4]. The BEACON trial recruited approximately 1,600 patients at 300 sites worldwide. However, it was terminated following observed safety concerns regarding bardoxolone methyl.

The BEAM investigators of the phase II trial have established a veritable, elaborate and systematic assessment method for the documentation and reporting of individual patientlevel, drug-related adverse events [1]. This measure should avert criticisms of previous CKD trials whose protocols often had major design deficiencies with poor systematic assessment and reporting of adverse effects of the study drug [2-4, 17]. In this trial, the testing and documentation of serum creatinine values in every study participant which were repeated every 4 weeks was laudable [1-4, 17]. It is hoped that such stringent, elaborate and meticulous attention concerning the identification and reporting of drug-related adverse events would even be improved upon in the ongoing global BEACON III bardoxolone methyl study. Some concerns about the implications of hypomagnesemia described among patients receiving bardoxolone methyl in the phase II trials were the subject of a recent correspondence to the editor of the NEJM $[1,18]$. Also, in the phase II trials, patients receiving bardoxolone methyl had slight but significant increases in the mean albumin creatinine ratio (ACR); however, the mechanism and potential implications for this observation remain unknown $[1,19,20]$. The higher drug discontinuation rate in the bardoxolone methyl arm is of some concern even though all the adverse events that triggered drug discontinuations generally resolved following discontinuation [1]. Hopefully, the ongoing global BEACON phase III bardoxolone methyl trial will help resolve some of these unanswered questions. 
Without prejudice to exogenous inulin-based or ${ }^{125}$ I-iothalamate-based clearance estimates of GFR, most nephrologists would agree that despite its limitations, measuring 24-hour urinary endogenous creatinine clearance remains the 'gold standard' for most clinical evaluations of renal function [21-23]. It is very pertinent to note that studies on 24-hour urinary creatinine clearance have never been carried out in the BEAM phase II clinical trial of bardoxolone methyl [1]. In the general nephrology community, it is hoped that the ongoing global BEACON bardoxolone methyl phase III trial protocol be modified to necessarily incorporate this test, even if only in a pre-specified percentage of the study participants. Otherwise, claims of increased eGFR by bardoxolone methyl treatment would continue to be greeted with doubts and reservations by many critics $[19,24]$. Indeed some correspondence to the editor of the NEJM, following the publication of the phase II bardoxolone methyl trial, raised veritable and genuine concerns regarding the assumption that the lower serum creatinine values recorded in the bardoxolone methyl arm truly represented improved kidney function (renoprotection) $[19,24]$. It has been argued that the lower serum creatinine values in the bardoxolone methyl arm of the BEAM study merely represented some artifactual findings related to either loss of muscle mass among participants in the bardoxolone methyl arm [19], increased intraglomerular hydrostatic pressure [20, 24], or even some other yet unidentified mechanism(s). We would like to reiterate that the BEACON investigators would considerably improve the ongoing global phase III trial and lend the study results more credibility if they incorporated 24-hour urinary creatinine measurements as part of the study protocol. Similar concerns regarding the non-performance of 24-hour urinary creatinine clearance measurements had been raised during question time following the presentation of the BEAM phase II clinical trial data at the International Society of Nephrology (ISN) meeting held in Vancouver, Canada, in April 2011.

\section{Variability of Serum Creatinine Values in CKD Patients: A Limitation to the eGFR-Based Assessment of Renoprotection in CKD Trials}

Another twist to this debate relates to the utilization of longitudinal changes in serum creatinine-based eGFR estimations to assess renoprotection in CKD trials. This has gained even more importance in recent years following the publication of new reports demonstrating considerable and clinically significant intra-patient variability in serum creatinine values over time [25-29]. This observed variability in serum creatinine trajectories in CKD patients is unpredictable, is not predicated on any clearly identifiable factors, and may be related sometimes to initiation and/or discontinuation of pharmaceutical agents, especially ACE inhibitors and ARBs [2-4, 25-39]. The patterns of this variability range from stability over several years, to various rates of decreasing eGFR and to improved and higher eGFR values over time, and it remains very unclear what factors are responsible for these variations in the level of serum creatinine among CKD patients [25-29]. The impact of such inherent and unpredictable intra-patient variability in serum creatinine trajectories in CKD patients over time, which may or may not be related to drug exposures and or drug discontinuations, and therefore with a potential for influencing CKD study outcomes, has never been addressed in previous CKD trials. This is a clear reason for major concern [27, 39]. Unfortunately, the nephrology literature has continued to totally refuse to address these limitations of overdependence on serum creatinine trajectories and serum creatinine-based eGFR in order to define renoprotection in CKD trials [27, 39].

The retrospective analysis of a 2-year snapshot of the serum creatinine trajectories of stage IV CKD patients with an eGFR of $15.0-29.9 \mathrm{ml} / \mathrm{min} / 1.73 \mathrm{~m}^{2}$ of body surface area has been recently completed in a Mayo Clinic electronic laboratory database [38, 39]. After 
excluding 62 ESRD patients and those who received renal replacement therapy, 241 patients qualified for this analysis [38, 39]. There were 102 males and 139 females, and in approximately $95 \%$ of the patients, the eGFR remained very stable and did not vary by as much as 5 eGFR points ( $<25 \%$ from baseline) over the 2 -year study period [38, 39]. We concluded that in the majority of stage IV CKD patients, the eGFR remains stable even after 2 years of followup and that current CKD staging paradigms are flawed $[38,39]$. The inability to account for the impact of such poorly understood or unknown confounding variables (i.e. serum creatinine variability in CKD patients) on study outcomes continues to pose a major challenge to the interpretation and analysis of RCT results in patients with CKD. This deficit introduces a threat to the internal validity of the statistical analyses - the phenomenon of ecological fallacy and Simpson's paradox $[40,41]$. Once again, these genuine concerns regarding inter-patient variability of the serum creatinine trajectories over time could be another valid reason to incorporate sequential 24-hour creatinine clearance measurements in the ongoing BEACON study [25-29, 38, 39].

\section{A Renewed Call for the Exclusive Use of Hard Renal Outcome End Points in CKD Renoprotection Trials: Stand-Alone ESRD Rates Should Be the 'Gold Standard'}

As already noted above, it is now increasingly apparent that the pattern of serum creatinine trajectories in CKD patients is often unpredictable and commonly variable. Furthermore, changes are sometimes related to drug initiation and/or drug discontinuation, particularly associated with ACE inhibitors and ARBs [25-39]. Therefore, it is mandatory that all ongoing BEACON phase III study participants must be on an ACE inhibitor and/or an ARB and that the analysis of kidney function in this study be necessarily vetted at the individual patient-data level, to reliably account for potential changes in kidney function that could follow certain drug terminations so as not to confound study outcome interpretations [26-39]. Thus, any circumstantial or incidental improvements in kidney function would not otherwise be erroneously ascribed to renoprotection and vice versa [26-39].

\section{Overuse of Combination Surrogate Renal End Points in Nephrology RCTs}

Another related concern is the overreliance on the so-called surrogates of renal function such as doubling of serum creatinine and reduction of proteinuria levels as the basis for determining and defining renoprotection [40]. The BEAM study confirmed in fact that bardoxolone methyl actually produced increased levels of albuminuria as measured by ACRs. Thus, it is another limitation to use the decrease in proteinuria levels as a measure of renoprotection $[1,24]$. Besides, in our single center experiences, we reported disassociations between kidney function and measured ACR in patients who demonstrated clearly improved kidney function following discontinuation of ACE inhibitors and/or ARBs while concurrently showing increased levels of ACR [30-37, 39]. In our opinion, the overreliance of the nephrology literature on the use of composite end points consisting of combinations of these so-called surrogate renal end points (i.e. doubling of serum creatinine, changes in proteinuria levels, and ESRD), to determine statistical differences in renal outcomes between study groups, is arguably flawed [40]. One major drawback of this approach is that the utilization of such potentially confounding variables, as if they represented independent variables, introduces a threat to the internal validity of the statistical analyses $[40,41]$. This statistical anomaly or fallacy is called the phenomenon of ecological fallacy or Simpson's paradox [40, 41]. In particular, the magnitude and even the direction of relationships between variables found by 
comparing group-level statistics may not be indicative of the same relationships tested with individual participant data [40-42]. Consequently, proof of association must not always be assumed to represent or translate to proof of causation [40]. In our opinion, Simpson's paradox ought to receive more attention in the nephrology literature, especially with crosstabulation analyses and meta-analyses of group-level patient data, and we strongly advocate the avoidance of the use of these combined surrogates in composite end point statistical analysis since we do not truly and fully understand the interplay between all these renal indices [40-43].

The one hard renal outcome end point that would be bereft of these encumbrances and statistical pitfalls and hazards, we submit, would be the exclusive use of incident ESRD rates, as defined by the irreversible and permanent need for renal replacement therapy for 90 days or longer, to evaluate and define renoprotection in CKD trials [39]. We therefore look forward to seeing the comparison of incident ESRD rates as primary stand-alone renal end points in the ongoing global BEACON bardoxolone methyl phase III clinical trial.

\section{Limitations of Current Renoprotection Paradigms Using Angiotensin Inhibition}

Additionally, we feel obligated to ask another more loaded question: Given the fact that, despite decades of widespread and extensive utilization of ACE inhibitors and ARBs in the USA and around the world, we have continued to experience progression of CKD to ESRD, with some authorities declaring the existence of a continuing global ESRD pandemic in recent years [2-7], is it not time to re-strategize on the current concepts of renoprotection? In a 2010 issue of the International Journal of Clinical Practice, we had asked a similarly loaded rhetorical question: Is renoprotection with RAAS blockade a failed paradigm? [3]. The next section is a critical reappraisal of the limitations of the current concept of renoprotection that is solely predicated on angiotensin blockade. This concept is scrutinized against the backdrop of the plausible existence of potentially multiple, disparately different and independent putative pathways and/or mechanisms that are mechanistically responsible for both the initiation and/or propagation of CKD to ESRD [2-4,39].

\section{Putative Pathogenetic Mechanisms for CKD Progression in Diabetic and Non-Diabetic Nephropathy - Can a Single Agent Truly and Consistently Deliver Renoprotection?}

Despite extensive research effort and time, it is still valid to postulate that in 2011, we do not have a complete and unquestionable knowledge yet of the mechanisms that trigger and/ or lead to CKD initiation and progression to ESRD, respectively [44]. In addition, current renoprotection paradigms depend wholly and entirely on the use of ACE inhibitors and/or ARBs [9-16]. On the contrary, the validity and soundness of such a model appear farfetched and almost indefensible, especially given the rather perplexing and confusing state of our current knowledge of the various putative pathologic mechanisms that are involved in the initiation and/or propagation of CKD to ESRD $[39,45]$. In a recent review, we analyzed the current literature on the putative, multiple independent and unrelated pathogenetic mechanisms that drive (diabetic and non-diabetic) CKD progression [4, 39]. These putative mechanisms are summarized below. Cognizant of the array and disparateness of these mechanisms of CKD propagation to ESRD, it seems naively unscientific and unpretentiously simplistic for practicing nephrologists to surmise that single mechanism-blocking agents, such as ACE inhibitors and/or ARBs, which can only antagonize the angiotensin cascade, would successfully, 
consistently and unfailingly deliver adequate and qualitative renoprotection results in (diabetic and non-diabetic) CKD patients [2-4, 39]. As is evident from our critical reviews documented in recent reports [2-4, 39], the conviction that a pharmaceutical agent capable of antagonizing just one single mechanism or pathway of CKD to ESRD progression, such as the angiotensin blocking agents, would be expected to represent the magic bullet to prevent CKD to ESRD evolution is simply unrealistic, improbable, remains only speculative and, worse still, flies in the face of reason [2-4,39]. This 'one size fits all' approach to medicine, in general, must be questioned and challenged, and in our opinion ought to be discouraged; its practice in CKD management is a debunked and unproven notion [2-4, 39].

First, even the exact anatomical site of the culprit damage to the kidneys underlying the development of albuminuria in diabetic nephropathy, which relates to the poor renal outcomes in diabetic nephropathy, remains questionable, controversial and ill-defined [46, 47]. As recently as 2009, Russo and colleagues [46, 47] reported new experimental evidence suggesting that tubular dysfunction might constitute the primary factor in the causation of early albuminuria from diabetic nephropathy as opposed to a glomerular pathology. Furthermore, Venkatachalam et al. [44] in a study on the impact of acute kidney injury (AKI) and post-AKI repair mechanisms concluded that the pathology that develops in regenerating tubules after AKI characterized by failure of differentiation and persistently high signaling activity is the proximate cause that drives downstream events in the interstitium (i.e. inflammation, capillary rarefaction and fibroblast proliferation).

Second, a critical and dispassionate review of the available literature in this regard will lead to the conclusion that the culprit pathogenetic molecule(s) or mechanistic factor(s) responsible for the initiation and propagation of diabetic and/or non-diabetic nephropathy, and subsequent CKD to ESRD progression, remain unverified, unconfirmed, uncertain, and possibly unknown [39, 48-70]. Undeniably, several independent and often conflicting lines of evidence in the literature, from both human and experimental studies, suggest that a variety of presumed pathogenetic culprit mechanisms and factors, such as oxidative stress, inflammation, underlying genetic predispositions and different chemical molecules capable of directly causing AKI, could be responsible for CKD to ESRD progression [39, 48-70]. The following is a listing of some of these reported mechanisms or factors:

- several predisposing genetic abnormalities including variations of the non-muscle myosin heavy chain 9 gene (MYH9) on chromosome 22 and variants at chromosome 6q24-27 among African-Americans [48-51];

- $\quad$ oxidative stress combined with a paradoxical hypoxic renal environment conditioned by an underlying genetic predisposition (see above) [50, 52];

- the production of advanced glycosylation end products and the interaction of these end products on the multiligand receptor of the immunoglobulin superfamily receptor for advanced glycation end products [53, 54];

- intrarenal angiotensin II and/or renin production [55];

- inflammation [56];

- lipid toxicity [57-59];

- podocyte injury and apoptosis [60,61];

- cytokine/chemokine/growth factor release causing renal injury [62, 63];

- asymmetric dimethylarginine [64];

- uric acid in CKD progression continues to attract increasing global attention [65-70].

As emerges from the foregoing, there is this overarching impetus to arrive at the inference that multiple, disparately diverse and independent pathways including any veritable combination of these mechanisms, and others yet to be identified, do concurrently and asymmetrically contribute to CKD initiation and propagation to ESRD in our CKD patients [39, 48-70]. Yet, more recently, new experimental and clinical evidence is accumulating to suggest a role 
for APOL1 variants in the pathogenesis and progression of CKD [71-74]. In addition, population-based genetic studies have identified many genetic variants of APOL1 that are associated with an increased risk of developing common kidney diseases including focal segmental glomerulosclerosis and HIV-1-associated nephropathy [71-75].

Therefore, we cannot claim to fully understand the natural history, pathology and pathogenesis of diabetic and non-diabetic renal kidney disease, its natural history, and the multiplicity of incriminated factors that influence CKD propagation and the development of ESRD $[6,7,38-40,45,48-74]$. The impact of AKI on the progression and development of ESRD is even more intriguing $[44,75]$. Our recent description of the previously unrecognized syndrome of rapid-onset ESRD in some of our patients, rapidly and sequentially following AKI events, is yet another twist to the narrative [75]. Indeed, Venkatachalam et al. [44] in a recent elaborate review, reported in the American Journal of Physiology, concluded that despite extensive effort and resources devoted to the investigation of CKD to ESRD progression, a full understanding of the underlying mechanisms has remained elusive. This study again demonstrated some pathologic linkages between AKI and progression from CKD to ESRD [44]. Finally, we want to re-echo the calls from around the world for clinical trials and further dispassionate in-depth study of these putative mechanisms in the form of adequately powered RCTs $[39,66,67,70]$.

We would like to end this review of renoprotection by discussing our new scheme of classification of renoprotective agents that is based on the number of putative mechanisms of CKD to ESRD progression that an individual pharmaceutical agent is capable of antagonizing or interfering with to produce the desired effects of renoprotection and therefore enhanced kidney survival [39].

\section{The Search for Novel Renoprotective Agents - A Case for More Effective Renoprotective Agents Capable of Simultaneously Attenuating Multiple Pathogenetic Pathways Involved in CKD to ESRD Progression: A Proposed New Classification Scheme for Renoprotective Agents}

As a final point, we support the ongoing and renewed search for newer and potentially more effective renoprotective agents $[1,3,4,39]$. ACE inhibitors and ARBs only block a single putative pathogenetic pathway involved in CKD progression: the angiotensin cascade $[2-4,55$, 76-79]. We named such renoprotective agents, which specifically block or antagonize a single mechanism or pathway, single-pathway blockers (SPBs) [39]. These SPBs, however, have the shortcoming to be unable to attenuate or antagonize other potentially important putative, independent and unrelated pathogenetic pathways or mechanisms that also drive CKD to ESRD progression $[4,39]$. In opposition, a renoprotective agent that is able to block or antagonize the effects of multiple pathogenetic pathways through its ability to simultaneously block, downstream, the effects of several pathways or mechanisms of CKD to ESRD progression would therefore concurrently interfere with several unrelated upstream pathways or mechanisms [39]. We named this group of (novel?) renoprotective agents multiple-pathway blockers (MPBs) [39]. In a recent publication, we proposed that these yet to be identified or developed agents - MPBs - may potentially prove to be more effective useful renoprotective agents than the currently available SPB agents exemplified and typified by ACE inhibitors and ARBs [39]. MPBs may possess the ability to even possibly reverse CKD progression, leading in fact to improved and higher eGFR values in CKD patients, as opposed to just slowing down CKD progression, which later benefit for now is the best that we could hope to get from the use of ACE inhibitors and ARBs [2-4, 9-16, 37, 39]. Only time will tell if any new MPB renoprotective agent will live up to this hope or hype of the prevention of ESRD [80]. 
By our new classification scheme, such MPB renoprotective agents would potentially include the new synthetic oleanane triterpenoid and antioxidant inflammation modulator bardoxolone methyl [1, 81-84], as well as the non-specific phosphor-diesterase inhibitor pentoxifylline, which suppresses the production of some factors of inflammatory response [85-87]. Bardoxolone methyl is an antioxidant inflammation modulator and the most potent known inducer of Nrf2 to enter clinical trials [84]. Nrf2 activates over 250 antioxidant and detoxification genes, improves endothelial function, and maintains kidney structure and function [84]. The BEAM study (the recently completed phase II trials investigating the new agent bardoxolone methyl) has been extensively reviewed earlier [1]. Correspondingly, phase II clinical trials with the drug pentoxifylline, which until now has been used mainly to treat patients with peripheral arterial disease, has also shown some promise for renoprotection among diabetic CKD patients [85, 86]. As noted by Renke et al. [85] in 2010, despite the use of ACE inhibitors and ARBs in the management of patients with CKD, there is no universal therapy that is currently available to physicians that can stop the progression of CKD. The result of the ongoing global BEACON phase III trial on the effect of bardoxolone methyl on CKD progression in type II diabetics with stage IV CKD remains highly anticipated within the nephrology community worldwide [1].

\section{Conclusions}

CKD, which used to be called chronic kidney failure, and its progression to ESRD requiring renal replacement therapy remain a major health problem worldwide, accounting for huge and increasing health care costs all around the world, both in developed countries and in the poorer developing countries [88-95]. Although current renoprotection paradigms are focused mainly on the blockade and antagonism of the renin-angiotensin system, we hypothesize that it is mandatory that new therapeutic modalities capable of simultaneously attenuating multiple and independent pathophysiological mechanisms and pathways, the so-called MPBs, must be developed and introduced into clinical medicine, and in quick order [39]. This critical mission is urgent, especially if we are to make any significant progress in our current efforts to slow down CKD to ESRD progression and to begin to retard the pace of the growing and costly global ESRD pandemic [39, 88].

\section{A Final Disclaimer - Limitations of Serum Creatinine-Based eGFR Measurements of Kidney Function}

We could not end this review without acknowledging the limitations of serum creatinine as a marker or surrogate of renal function as it is related to renoprotection measurements. By current convention, the degree of CKD is expressed in terms of GFR, which can be determined directly or estimated according to different formulas on the basis of serum creatinine [96]. Eloot et al. [96] studied the associations between eGFR based on serum cystatin C and different uremic solutes (with a molecular weight range of 113-240 Da; determined by colorimetry, HPLC, or ELISA) in 95 CKD patients not on dialysis (stage II-V CKD). The same analysis was also applied to six other eGFR formulas. There was a substantial disparity in fits among solutes. In linear regression, explained variance of eGFR was extremely low for most solutes, with an eGFR $>0.4$ only for creatinine [96]. The other eGFR formulations gave comparably disappointing results with regard to their association to uremic solutes. In this elaborate analysis, the authors concluded that the eGFR is poorly associated with concentrations of all studied uremic toxins in patients with different degrees of CKD, correlates differently 
with each individual solute, and can thus not be considered representative for evaluating the accumulation of solutes in the course of CKD [96]. The search for alternatives to a creatininebased estimation of the GFR in trials of renoprotection and progression should therefore be continued [96]. In a more recent and related commentary, Vanholder et al. [97] concluded that the eGFR is a deceiving predictor of uremic solute concentrations and their biological action. The authors noted that this inconsistency is very likely the result of the impact of other factors affecting concentration, such as tubular secretion, generation by intestinal flora and metabolism.

\section{Epilogue}

Our epilogue in a recent book publication raised the hope of a better tomorrow in nephrology care around the world. Our hope in publishing the book was to rekindle new thinking and re-engineering in the way we do things in medicine, especially in renal medicine or nephrology [39]. We hope to enable and encourage the practitioner of the art of medicine, both nephrologists and non-nephrology physicians alike, to question long held paradigms particularly in the face of evidence to the contrary, for physicians to strive to do no harm to the (CKD) patient, and for all of us to continue to endeavor to improve patient and renal outcomes in CKD management [39]. If we manage to attain these lofty patient management goals, we would have achieved the objective that we set out to accomplish in completing this book project earlier in the summer of 2011 [39]. We indeed remain very hopeful for the future.

\section{Disclosure Statement}

The author has no conflicts of interest to declare.

\section{References}

1 Pergola PE, Raskin P, Toto RD, Meyer CJ, Huff JW, et al: Bardoxolone methyl and kidney function in CKD with type 2 diabetes. N Eng J Med 2011;365:327-336.

$\rightarrow 2$ Onuigbo MA: Reno-prevention versus renoprotection: a critical re-appraisal of the evidence-base from the large RAAS blockade trials after ONTARGET - a call for more circumspection. QJM 2009;102:155-167.

-3 Onuigbo MA: Is renoprotection with RAAS blockade a failed paradigm? Have we learnt any lessons so far? Int J Clin Pract 2010;64:1341-1346.

4 Onuigbo MA: Can ACE inhibitors and angiotensin receptor blockers be detrimental in CKD patients? Nephron Clin Pract 2011;118:c407-c419.

5 Hsu CY, Vittinghoff E, Lin F, Shlipak MG: The incidence of end-stage renal disease is increasing faster than the prevalence of chronic renal insufficiency. Ann Intern Med 2004;141:95-101.

6 Szczech LA, Lazar IL: Projecting the United States ESRD population: issues regarding treatment of patients with ESRD. Kidney Int Suppl 2004;90:S3-S7.

7 Jones CA, Krolewski AS, Rogus J, Xue JL, Collins A, Warram JH: Epidemic of end-stage renal disease in people with diabetes in the United States population: do we know the cause? Kidney Int 2005;67:1684-1691.

8 Svensson P, de Faire U, Sleight P, Yusuf S, Ostergren J: Comparative effects of ramipril on ambulatory and office blood pressures: a HOPE Substudy. Hypertension 2001;38:E28-E32.

-9 Lewis EJ, Hunsicker LG, Bain RP, Rohde RD: The effect of angiotensin-converting-enzyme inhibition on diabetic nephropathy. The Collaborative Study Group. N Engl J Med 1993;329:1456-1462 (erratum published in N Engl J Med 1993;330:152).

10 Ruggenenti P, Perna A, Gherardi G, Garini G, Zoccali C, Salvadori M, et al: Renoprotective properties of ACEinhibition in non-diabetic nephropathies with non-nephrotic proteinuria. Lancet 1999;354:359-364.

11 Heart Outcomes Prevention Evaluation (HOPE) Study Investigators: Effects of ramipril on cardiovascular and microvascular outcomes in people with diabetes mellitus: results of the HOPE study and MICRO-HOPE substudy. Lancet 2000;355:253-259 (erratum published in Lancet 2000;356:860). 
12 Mogensen CE, Neldam S, Tikkanen I, Oren S, Viskoper R, Watts RW, et al: Randomised controlled trial of dual blockade of renin-angiotensin system in patients with hypertension, microalbuminuria, and non-insulin dependent diabetes: the candesartan and lisinopril microalbuminuria (CALM) study. BMJ 2000;321:14401444.

13 Parving HH, Lehnert H, Brochner-Mortensen J, Gomis R, Andersen S, Arner P: The effect of irbesartan on the development of diabetic nephropathy in patients with type 2 diabetes. N Engl J Med 2001;345:870-878.

14 Brenner BM, Cooper ME, de Zeeuw D, Keane WF, Mitch WE, Parving HH, et al: Effects of losartan on renal and cardiovascular outcomes in patients with type 2 diabetes and nephropathy. N Engl J Med 2001;345:861-869.

15 Lewis EJ, Hunsicker LG, Clarke WR, Berl T, Pohl MA, Lewis JB, et al: Renoprotective effect of the angiotensinreceptor antagonist irbesartan in patients with nephropathy due to type 2 diabetes. N Engl J Med 2001;345: 851-860.

16 Yusuf S, Teo KK, Pogue J, Dyal L, Copland I, Schumacher H, et al; ONTARGET Investigators: Telmisartan, ramipril, or both in patients at high risk for vascular events. N Engl J Med 2008;358:1547-1559.

17 Kunz R, Friedrich C, Wolbers M, Mann JF: Meta-analysis: effect of monotherapy and combination therapy with inhibitors of the renin angiotensin system on proteinuria in renal disease. Ann Intern Med 2008;148:30-48.

18 Van Laecke S, Vanholder R: Bardoxolone methyl, chronic kidney disease, and type 2 diabetes. N Engl J Med 2011;365:1745; author reply 1746-1747.

19 Rogacev KS, Bittenbring JT, Fliser D: Bardoxolone methyl, chronic kidney disease, and type 2 diabetes. N Engl J Med 2011;365:1745-1746; author reply 1746-1747.

20 McMahon GM, Forman JP: Bardoxolone methyl, chronic kidney disease, and type 2 diabetes. N Engl J Med 2011; 365:1746; author reply 1746-1747.

21 Martini S, Prévot A, Mosig D, Werner D, van Melle G, Guignard JP: Glomerular filtration rate: measure creatinine and height rather than cystatin C! Acta Paediatr 2003;92:1052-1057.

-22 De Santo NG, Anastasio P, Cirillo M, Santoro D, Spitali L, Mansi L, Celentano L, Capodicasa D, Cirillo E, Del Vecchio E, Pascale C, Capasso G: Measurement of glomerular filtration rate by the $99 \mathrm{mTc}$-DTPA renogram is less precise than measured and predicted creatinine clearance. Nephron 1999;81:136-140.

23 Okada N, Imanishi M, Yoshioka K, Konishi Y, Okumura M, Tanaka S, Fujii S: Creatinine clearance as a substitute for the glomerular filtration rate in the assessment of glomerular hemodynamics. Hypertens Res 1999;22: 279-284.

24 Upadhyay A, Sarnak MK, Levey AS: Bardoxolone methyl, chronic kidney disease, and type 2 diabetes. N Engl J Med 2011;365:1745; author reply 1746-1747.

25 Levin A, Djurdjev 0, Beaulieu M, Er L: Variability and risk factors for kidney disease progression and death following attainment of stage 4 CKD in a referred cohort. Am J Kidney Dis 2008;52:661-671.

26 Sikaneta T, Abdolell M, Taskapan H, Roscoe J, Fung J, Nagai G, Ting RH, Ng P, Wu G, Oreopoulos D, Tam PY: Variability in CKD stage in outpatients followed in two large renal clinics. Int Urol Nephrol 2011, E-pub ahead of print.

27 Onuigbo MA, Onuigbo NT: Variability in CKD stage in outpatients followed in two large renal clinics: implications for CKD trials and the status of current knowledge of patterns of CKD to ESRD progression. Int Urol Nephrol 2011, E-pub ahead of print.

-28 Sikaneta T, Roscoe J, Fung J, Nagai G, Ting RH, Ng P, Tam PY, Abdolell M, Taskapan H, Oreopoulos D, Wu G: Variability in CKD stage in outpatients followed in two large renal clinics: implications for CKD trials and the status of current knowledge of patterns of CKD to ESRD progression: response to Dr. Onuigbo. Int Urol Nephrol 2011, E-pub ahead of print.

29 Ahmed AK, Kamath NS, El Kossi M, El Nahas AM: The impact of stopping inhibitors of the renin-angiotensin system in patients with advanced chronic kidney disease. Nephrol Dial Transplant 2010;25:3977-3982.

-30 Onuigbo MA, Onuigbo NT: Late onset renal failure from angiotensin blockade (LORFFAB): a prospective thirtymonth Mayo Health System clinic experience. Med Sci Monit 2005;11:CR462-CR469.

-31 Onuigbo MA, Onuigbo NT: Late-onset renal failure from angiotensin blockade (LORFFAB) in 100 CKD patients. Int Urol Nephrol 2008;40:233-239.

-32 Onuigbo MA, Onuigbo NT: Does renin-angiotensin aldosterone system blockade exacerbate contrast-induced nephropathy in patients with chronic kidney disease? A prospective 50-month Mayo Clinic study. Ren Fail 2008;30:67-72.

-33 Onuigbo MA, Onuigbo NT: Late onset azotemia from RAAS blockade in CKD patients with normal renal arteries and no precipitating risk factors. Ren Fail 2008;30:73-80.

-34 Onuigbo MA, Onuigbo NT: Worsening renal failure in older chronic kidney disease patients with renal artery stenosis concurrently on renin angiotensin aldosterone system blockade: a prospective 50-month MayoHealth-System clinic analysis. QJM 2008;101:519-527.

-35 Onuigbo MA, Onuigbo NT: Renal failure and concurrent RAAS blockade in older CKD patients with renal artery stenosis: an extended Mayo Clinic prospective 63-month experience. Ren Fail 2008;30:363-371.

36 Onuigbo MA: An analytical review of the evidence-base for reno-protection from the large RAAS blockade trials after ONTARGET. Re-visitation of the potential for iatrogenic renal failure with RAAS blockade? A call for caution. Nephron Clin Pract 2009;113:c63-c69.

-37 Onuigbo MA: The natural history of chronic kidney disease revisited - a 72-month Mayo Health System Hypertension Clinic practice-based research network prospective report on end-stage renal disease and death rates in 100 high-risk chronic kidney disease patients: a call for circumspection. Adv Perit Dial 2009;25:85-88 
Onuigbo MA: The Validity of current CKD staging paradigms revisited and disputed: a 2-year snap shot of stage IV CKD patients in a Mayo Clinic laboratory database: a call for process reengineering in nephrology practice (abstract). J Am Soc Nephrol 2011;22:686A [SA-P02472]. Onuigbo MA, Onuigbo N: Chronic Kidney Disease and RAAS Blockade: A New View of Renoprotection. London, Lambert Academic Publishing GmbH \& Co. KG., 2011.

40 Onuigbo MA: Relation between kidney function, proteinuria, and adverse outcomes - a critical look at the application of medical statistics in the Nephrology literature. QJM 2010;103:537-538.

41 Ameringer S, Serlin RC, Ward S: Simpson's paradox and experimental research. Nurs Res 2009;58:123-127.

$\checkmark 42$ Cooper H, Patall EA: The relative benefits of meta-analysis conducted with individual participant data versus aggregated data. Psychol Methods 2009;14:165-176.

43 Riley RD, Lambert PC, Staessen JA, et al: Meta-analysis of continuous outcomes combining individual patient data and aggregate data. Statist Med 2008;27:1870-1893.

44 Venkatachalam MA, Griffin KA, Lan R, Geng H, Saikumar P, Bidani AK: Acute kidney injury: a springboard for progression in chronic kidney disease. Am J Physiol Renal Physiol 2010, E-pub ahead of print.

45 Onuigbo MA: Causes of renal failure in patients with type 2 diabetes mellitus. JAMA 2003;290:1855; author reply $1855-1856$.

46 Comper WD, Hilliard LM, Nikolic-Paterson DJ, Russo LM: Disease-dependent mechanisms of albuminuria. Am J Physiol Renal Physiol 2008;295:F1589-F1600.

47 Russo LM, Sandoval RM, Campos SB, Molitoris BA, Comper WD, Brown D: Impaired tubular uptake explains albuminuria in early diabetic nephropathy. J Am Soc Nephrol 2009;20:489-494.

-48 Freedman BI, Hicks PJ, Bostrom MA, Comeau ME, Divers J, Bleyer AJ, Kopp JB, Winkler CA, Nelson GW, Langefeld CD, Bowden DW: Non-muscle myosin heavy chain 9 gene MYH9 associations in African Americans with clinically diagnosed type 2 diabetes mellitus-associated ESRD. Nephrol Dial Transplant 2009;24:3366-3371.

49 Leak TS, Mychaleckyj JC, Smith SG, Keene KL, Gordon CJ, Hicks PJ, Freedman BI, Bowden DW, Sale MM: Evaluation of a SNP map of 6q24-27 confirms diabetic nephropathy loci and identifies novel associations in type 2 diabetes patients with nephropathy from an African-American population. Hum Genet 2008;124:63-71.

-50 Forbes JM, Coughlan MT, Cooper ME: Oxidative stress as a major culprit in kidney disease in diabetes. Diabetes 2008;57:1446-1454.

51 Singh DK, Winocour P, Farrington K: Mechanisms of disease: the hypoxic tubular hypothesis of diabetic nephropathy. Nat Clin Pract Nephrol 2008;4:216-226.

52 Swaminathan S, Shah SV: Novel approaches targeted toward oxidative stress for the treatment of chronic kidney disease. Curr Opin Nephrol Hypertens 2008;17:143-148.

53 Goh SY, Cooper ME: Clinical review: the role of advanced glycation end products in progression and complications of diabetes. J Clin Endocrinol Metab 2008;93:1143-1152.

-54 Flyvbjerg A, Denner L, Schrijvers BF, Tilton RG, Mogensen TH, Paludan SR, Rasch R: Long-term renal effects of a neutralizing RAGE antibody in obese type 2 diabetic mice. Diabetes 2004;53:166-172.

-55 Park S, Bivona BJ, Kobori H, Seth DM, Chappell MC, Lazartigues E, Harrison-Bernard LM: Major role for ACEindependent intrarenal ANG II formation in type II diabetes. Am J Physiol Renal Physiol 2010;298:F37-F48.

56 Matavelli LC, Huang J, Siragy HM: (Pro)renin receptor contributes to diabetic nephropathy by enhancing renal inflammation. Clin Exp Pharmacol Physiol 2010;37:277-282.

-57 Sasaki H, Kamijo-Ikemori A, Sugaya T, Yamashita K, Yokoyama T, Koike J, Sato T, Yasuda T, Kimura K: Urinary fatty acids and liver-type fatty acid binding protein in diabetic nephropathy. Nephron Clin Pract 2009; 112:c148-c156.

58 Lennon R, Pons D, Sabin MA, Wei C, Shield JP, Coward RJ, Tavare JM, Mathieson PW, Saleem MA, Welsh GI: Saturated fatty acids induce insulin resistance in human podocytes: implications for diabetic nephropathy. Nephrol Dial Transplant 2009;24:3288-3296.

59 An WS, Kim HJ, Cho KH, Vaziri ND: Omega-3 fatty acid supplementation attenuates oxidative stress, inflammation, and tubulointerstitial fibrosis in the remnant kidney. Am J Physiol Renal Physiol 2009;297:F895-F903.

-60 Yilmaz MI, Saglam M, Qureshi AR, Carrero JJ, Caglar K, Eyileten T, Sonmez A, Cakir E, Oguz Y, Vural A, Yenicesu M, Stenvinkel P, Lindholm B, Axelsson J: Endothelial dysfunction in type-2 diabetics with early diabetic nephropathy is associated with low circulating adiponectin. Nephrol Dial Transplant 2008;23:1621-1627.

61 Yamaguchi Y, Iwano M, Suzuki D, Nakatani K, Kimura K, Harada K, Kubo A, Akai Y, Toyoda M, Kanauchi M, Neilson EG, Saito Y: Epithelial-mesenchymal transition as a potential explanation for podocyte depletion in diabetic nephropathy. Am J Kidney Dis 2009;54:653-664.

62 Yokoi H, Mukoyama M, Mori K, Kasahara M, Suganami T, Sawai K, Yoshioka T, Saito Y, Ogawa Y, Kuwabara T, Sugawara A, Nakao K: Overexpression of connective tissue growth factor in podocytes worsens diabetic nephropathy in mice. Kidney Int 2008;73:446-455.

-63 Jaffa AA, Usinger WR, McHenry MB, Jaffa MA, Lipstiz SR, Lackland D, Lopes-Virella M, Luttrell LM, Wilson PW: Connective tissue growth factor and susceptibility to renal and vascular disease risk in type 1 diabetes. J Clin Endocrinol Metab 2008;93:1893-1900.

-64 Fujimi-Hayashida A, Ueda S, Yamagishi S, Kaida Y, Ando R, Nakayama Y, Fukami K, Okuda S: Association of asymmetric dimethylarginine with severity of kidney injury and decline in kidney function in IgA nephropathy. Am J Nephrol 2011;33:1-6.

65 Chonchol M, Shlipak MG, Katz R, Sarnak MJ, Newman AB, Siscovick DS, Kestenbaum B, Carney JK, Fried LF: Relationship of uric acid with progression of kidney disease. Am J Kidney Dis 2007;50:239-247. 
66 Yen CJ, Chiang CK, Ho LC, Hsu SH, Hung KY, Wu KD, Tsai TJ: Hyperuricemia associated with rapid renal function decline in elderly Taiwanese subjects. J Formos Med Assoc 2009;108:921-928.

67 Feig DI: Uric acid: a novel mediator and marker of risk in chronic kidney disease? Curr Opin Nephrol Hypertens 2009;18:526-530.

68 Kuo CF, Luo SF, See LC, Ko YS, Chen YM, Hwang JS, Chou IJ, Chang HC, Chen HW, Yu KH: Hyperuricaemia and accelerated reduction in renal function. Scand J Rheumatol 2011;40:116-121.

69 Bellomo G, Venanzi S, Verdura C, Saronio P, Esposito A, Timio M: Association of uric acid with change in kidney function in healthy normotensive individuals. Am J Kidney Dis 2010;56:264-272.

70 Badve SV, Brown F, Hawley CM, Johnson DW, Kanellis J, Rangan GK, Perkovic V: Challenges of conducting a trial of uric-acid-lowering therapy in CKD. Nat Rev Nephrol 2011;7:295-300.

71 Tzur S, Rosset S, Shemer R, Yudkovsky G, Selig S, Tarekegn A, Bekele E, Bradman N, Wasser WG, Behar DM, Skorecki K: Missense mutations in the APOL1 gene are highly associated with end stage kidney disease risk previously attributed to the MYH9 gene. Hum Genet 2010;128:345-350.

72 Behar DM, Kedem E, Rosset S, Haileselassie Y, Tzur S, Kra-Oz Z, Wasser WG, Shenhar Y, Shahar E, Hassoun G, Maor C, Wolday D, Pollack S, Skorecki K: Absence of APOL1 risk variants protects against HIV-associated nephropathy in the Ethiopian population. Am J Nephrol 2011;34:452-459.

-73 Kopp JB, Nelson GW, Sampath K, Johnson RC, Genovese G, An P, Friedman D, Briggs W, Dart R, Korbet S, Mokrzycki MH, Kimmel PL, Limou S, Ahuja TS, Berns JS, Fryc J, Simon EE, Smith MC, Trachtman H, Michel DM, Schelling JR, Vlahov D, Pollak M, Winkler CA: APOL1 genetic variants in focal segmental glomerulosclerosis and HIV-associated nephropathy. J Am Soc Nephrol 2011;22:2129-2137.

74 Papeta N, Kiryluk K, Patel A, Sterken R, Kacak N, Snyder HJ, Imus PH, Mhatre AN, Lawani AK, Julian BA, Wyatt RJ, Novak J, Wyatt CM, Ross MJ, Winston JA, Klotman ME, Cohen DJ, Appel GB, D’Agati VD, Klotman PE, Gharavi AG: APOL1 variants increase risk for FSGS and HIVAN but not IgA nephropathy. J Am Soc Nephrol 2011;22: 1991-1996.

75 Onuigbo MA: Syndrome of rapid-onset end-stage renal disease: a new unrecognized pattern ofCKD progression to ESRD. Ren Fail 2010;32:954-958.

76 Onuigbo MA: Angiotensin II receptor antagonists: what future? South Med J 1998;91:794-796.

77 Ballermann BJ, Onuigbo MA: Angiotensins; in Fray JCS (ed): Handbook of Physiology. New York, Oxford University Press, 2000, section 7: The endocrine system, vol 3: Endocrine regulation of water and electrolyte balance, pp 104-155.

78 Onuigbo MA, Weir MR: Evidence-based treatment of hypertension in patients with diabetes mellitus. Diabetes Obes Metab 2003;5:13-26.

79 Onuigbo MA, Onuigbo NTC: Angiotensin converting enzyme inhibitors; in DeBrue AN (ed): Angiotensin Converting Enzyme Inhibitors. New York, Nova Biomedical Books, Nova Science Publishers, 2009, pp 1-41. Hostetter TH: Prevention of end-stage renal disease due to type 2 diabetes. N Engl J Med 2001;345:910-912.

-81 Wu QQ, Wang Y, Senitko M, Meyer C, Wigley WC, Ferguson DA, Grossman E, Chen J, Zhou XJ, Hartono J, Winterberg P, Chen B, Agarwal A, Lu CY: Bardoxolone methyl (BARD) ameliorates ischemic AKI and increases expression of protective genes Nrf2, PPAR $\gamma$, and HO-1. Am J Physiol Renal Physiol 2011, E-pub ahead of print.

82 Sporn MB, Liby KT, Yore MM, Fu L, Lopchuk JM, Gribble GW: New synthetic triterpenoids: potent agents for prevention and treatment of tissue injury caused by inflammatory and oxidative stress. J Nat Prod 2011;74: 537-545.

83 Honda T, Yoshizawa H, Sundararajan C, David E, Lajoie MJ, Favaloro FG, Janosik T, Su X, Honda Y, Roebuck BD, Gribble GW: Tricyclic compounds containing nonenolizable cyano enones. A novel class of highly potent antiinflammatory and cytoprotective agents. J Med Chem 2011;54:1762-1778.

84 Pergola PE, Krauth M, Huff JW, Ferguson DA, Ruiz S, Meyer CJ, Warnock DG: Effect of bardoxolone methyl on kidney function in patients with T2D and stage 3b-4 CKD. Am J Nephrol 2011;33:469-476.

85 Renke M, Tylicki L, Rutkowski P, Knap N, Zietkiewicz M, Neuwelt A, Aleksandrowicz E, Łysiak-Szydłowska W, Woźniak M, Rutkowski B: Effect of pentoxifylline on proteinuria, markers of tubular injury and oxidative stress in non-diabetic patients with chronic kidney disease - placebo controlled, randomized, cross-over study. Acta Biochim Pol 2010;57:119-123.

-86 Navarro-González JF, Muros M, Mora-Fernández C, Herrera H, Meneses B, García J: Pentoxifylline for renoprotection in diabetic nephropathy: the PREDIAN study. Rationale and basal results. J Diabetes Complications 2010, E-pub ahead of print.

-87 Barkhordari K, Karimi A, Shafiee A, Soltaninia H, Khatami MR, Abbasi K, Yousefshahi F, Haghighat B, Brown V: Effect of pentoxifylline on preventing acute kidney injury after cardiac surgery by measuring urinary neutrophil gelatinase - associated lipocalin. J Cardiothorac Surg 2011;6:8.

88 Shah SV: Progress toward novel treatments for chronic kidney disease. J Ren Nutr 2010;20(5 suppl):S122S126.

89 Chugh KS, Jha V: Differences in the care of ESRD patients worldwide: required resources and future outlook. Kidney Int Suppl 1995;50:S7-S13.

90 Ursea N, Mircescu G, Constantinovici N, Verzan C: Nephrology and renal replacement therapy in Romania. Nephrol Dial Transplant 1997;12:684-690.

91 Lysaght MJ: Maintenance dialysis population dynamics: current trends and long-term implications. J Am Soc Nephrol 2002;13(suppl 1):S37-S40. 
92 Jha V: End-stage renal care in developing countries: the India experience. Ren Fail 2004;26:201-208.

$\$ 93$ Jha V: Current status of end-stage renal disease care in South Asia. Ethn Dis 2009;19(suppl 1):S1-27-32.

$\$ 94$ Ayodele OE, Alebiosu CO: Burden of chronic kidney disease: an international perspective. Adv Chronic Kidney Dis 2010;17:215-224.

$\$ 95$ Ulasi II, Ijoma CK: The enormity of chronic kidney disease in Nigeria: the situation in a teaching hospital in South-East Nigeria. J Trop Med 2010;2010:501957.

-96 Eloot S, Schepers E, Barreto DV, Barreto FC, Liabeuf S, et al: Estimated glomerular filtration rate is a poor predictor of concentration for a broad range of uremic toxins. Clin J Am Soc Nephrol 2011;6:1266-1273.

-97 Vanholder R, Eloot S, Schepers E, Neirynck N, Glorieux G, Massy Z: An Obituary for GFR as the main marker for kidney function? Semin Dial 2012;25:9-14. 